\title{
THE APPLICATION OF DATA ENVELOPMENT ANALYSIS FOR EVALUATION OF EFFICIENCY OF HEALTHCARE DELIVERY FOR CVD PATIENTS
}

\section{Kristína Kočišová1, Małgorzata Cygańska², Magdalena Kludacz-Alessandri ${ }^{3}$}

\footnotetext{
1 Technical University of Kosice, Faculty of Economics, Slovakia, ORCID: 0000-0003-0784-441X, Kristina.Kocisova@tuke.sk;

2 University of Warmia and Mazury in Olsztyn, Faculty of Economics, Poland, ORCID: 0000-0003-4548-2915, m.cyganska@uwm.edu.pl;

3 Warsaw University of Technology, College of Economics and Social Sciences in Plock, Poland, ORCID: 0000-00027011-2302, Magdalena.Kludacz@pw.edu.pl.
}

\begin{abstract}
The focus placed on the efficiency of the healthcare system can vary across the countries. This paper aims to analyse and compare the technical efficiency of medical care for CVD patients across selected OECD countries using the data envelopment analysis (DEA) method according to two models. The first model (TE) incorporates the quantitative outputs that are connected with the quantity of the hospital outcomes (the number of surgical operations and procedures related to disease of the circulatory system per 100,000 inhabitants; hospital discharge rates for in-patients with diseases of the circulatory system). The second model (QE) includes the quality outputs that are connected with the health outcomes (survival rates of patients with diseases of the circulatory system). A number of cardiologists and angiography equipment per 100,000 inhabitants and total healthcare costs of CVD patients per 100,000 inhabitants were considered as inputs in both models. Secondly, we analyse whether endogenous (institutional arrangements) and exogenous (population behaviour, economic determinants) factors are associated with the efficiency of medical care. We utilise Data Envelopment Analysis (DEA) to calculate the efficiency of medical care for CVD patients in selected OECD countries and establish healthcare systems' rankings according to $T E$ and efficient healthcare delivery for CVD patients. The study found that the technically efficient countries were not as far efficient when the quality measure was used to calculation of efficiency. On the other hand, some of the technically inefficient countries were performing well concerning efficiency based on a quality measure.
\end{abstract}

Keywords: Healthcare system efficiency, OECD countries, DEA analysis, efficiency of healthcare delivery, CVD patients.

JEL Classification: 118, M41.

APA Style Citation: Kočišová, K., Cygańska, M., \& Kludacz-Alessandri, M. (2020). The Application of Data Envelopment Analysis for Evaluation of Efficiency of Healthcare Delivery for CVD Patients. E\&M Economics and Management, 23(2), 96-113. https://doi.org/10.15240/ $\mathrm{tul} / 001 / 2020-2-007$

\section{Introduction}

Leading cause of death in Europe and worldwide are cardiovascular diseases (CVDs). According to AstraZeneca (2014), they are estimated to account for $31 \%$ of all global deaths, $47 \%$ of all deaths in Europe and $40 \%$ of all deaths in the European Union (EU). The economic costs to societies of cardiovascular 
problems are enormous, including sick leave and lost employment, reduced efficiency at work and premature mortality. Patients with CVD cost the EU economy around 210 billion EUR per year. As mentioned by Wilkins et al. (2017), funding for CVDs as a proportion of the total health budget in the EU is estimated to account for $8 \%$, and it ranges from around $19 \%$ in Hungary to around 3\% in other countries like Denmark, Sweden and Ireland. Around $53 \%$ of the total cost is due to direct healthcare costs, $26 \%$ to productivity losses and $21 \%$ to the informal care of people with CVD. The relatively significant burden of cardiovascular diseases and a high level of resources allocated to healthcare delivery for CVD patients makes the performance in this health area very critical important issue.

One of the key indicators of healthcare system performance is efficiency. Gavurova and Soltes (2016) defined efficiency as the level of output that can be obtained from a given mix of inputs. However, healthcare delivery systems involve multiple inputs and outputs. The appropriate way to measure health delivery performance is the use of an analytical method which combines the possible number of inputs and outputs for technical efficiency analysis. Technical efficiency is promoted as an adequate measure to evaluate and compare public sector and not-for-profit activities performance which are prevalent in the hospital sector. According to Hadad et al. (2013), technical efficiency can be defined as the maximum output that can be generated by a unit or, the production of a given unit of output investing minimum inputs. In healthcare, it can signify the capacity of the observed healthcare unit (e.g. hospital) to maximise the outcomes of healthcare delivery about available resources and constraints, or inversely the ability to minimise the resource consumption while maintaining appropriate outcomes of healthcare delivery (Soltes \& Gavurova, 2014; De-Pablos-Heredero, Fernández-Renedo, \& Medina-Merodio, 2015). In this paper, technical efficiency concerns the extent to which a country provides the maximum output from a given set of inputs. As reported by Simar and Wilson (2007), Data Envelopment Analysis (DEA) is a useful technique to evaluate the performance of the organisations in terms of technical and allocative efficiency.

This paper aims to examine the feasibility of quantitative cross-country comparison of healthcare systems' technical efficiency by exploiting available data on the use of resources, health expenditure and health outcomes in selected OECD countries. We use different input and output factors that are contributing to hospital performance in treating cardiovascular diseases. We employ DEA to analyse the efficiency of healthcare delivery for CVD patients using outputs based on the measure of quality and compare the results to the standard technical efficiency DEA model that uses quantitative outputs. We also examine whether the population health-related behaviour is associated with the efficiency of healthcare delivery for CVD patients.

Our research question asks what the consequences are to use different quantitative and qualitative variables as outputs to analyse the technical efficiency of healthcare delivery for CVD patients in a cross-country context. We checked if the application efficiency indicators based on the quality variables as outputs in the DEA models change the results of the analysis of the efficiency of healthcare delivery.

Our study estimates healthcare systems' efficiency, intending to add two additional contributions to literature. Firstly, we compare the relative efficiency of medical care for CVD patients across selected OECD countries. Secondly, we assess the impact of potential exogenous factors on technical efficiency in the analysed area. They are related to the consumption of alcohol, oil, vegetables, fruits, fishes and frequency of exercising. We proposed to use Data Envelopment Analysis (DEA) to distinguish the groups of countries that have low or high performance in terms of technical efficiency. This method was used in this study to benchmark both models of the efficiency of healthcare delivery: technical efficiency based on quantitative outputs (TE) and technical efficiency based on quality outputs (QE).

We first discuss previous studies regarding efficiency analysis in the healthcare sector, followed by the explanation of data envelopment analysis methodology used to calculate the efficiency of healthcare delivery for CVD patients. Then we examine our DEA model results regarding the cross-country efficiency analysis and impact of various healthrelated behaviours on this efficiency. Finally, we discuss the results, conclude and provide further research directions. 


\section{Literature Review}

According to Bhat (2005), most applications of DEA in healthcare have been in the evaluation of micro-level service efficiency. The efficiency of healthcare delivery of cardiovascular diseases has previously been measured in national contexts (e.g. Adang, Gerritsma, Nouwens, van Lieshout, \& Wensing, 2016; Szabo, Mihalčová, Gallo, \& Ivaničková, 2018), but not in a crosscountry context. As mentioned by Hadad, Hadad and Simon-Tuval (2013), the measurement of efficiency taken in a cross-country analysis is a complex problem, partially due to a lack of reliable databases with uniform definitions of health inputs and outputs. There is a significant gap in the literature to conduct quantitative cross-country comparisons for the technical efficiency of healthcare delivery focusing on cardiovascular diseases (CVD patients). There have been some cross-country comparative studies in the area of measuring the efficiency of healthcare delivery, but they were related to other health diseases (Moran \& Jacobs, 2013; Ozgen \& Ozcan, 2002; Bartak \& Gavurova, 2015) or the overall healthcare system (Afonso \& St. Aubyn, 2005; Bhat, 2005; Hernandez de Cos \& Moral-Benito, 2014; Retzlaff-Roberts, Chang, \& Rubin, 2004; Spinks \& Hollingsworth, 2009).

Data envelopment analysis (DEA) is the most commonly used approach for performance evaluation of healthcare systems (Greene, 2004; Hollingsworth, 2008; Jacobs, 2001). It is a quantitative technique developed by Charnes, Cooper and Rhodes (1978). The DEA is based on linear programming that computes technical efficiency scores for decision-making units (DMUs) relative to their peer units (it means in comparison to a best-practice production frontier). This method is used to develop an efficiency frontier for the DMUs that operate with optimal performance patterns. One of the main advantages of the DEA method is that it can incorporate more than one input or output. Besides this advantage, the other is that DEA does not require a mathematical specification of production frontier, it is unrelated to standard data partitioning, it is the most appropriate method for the use of exogenous variables, it provides target input and outputs for the inefficient unit to achieve efficiency, and so on.

On the other hand, the main limitations of DEA are:
- the results are sensitive to the choice of inputs and outputs, sensitive to the presence of incorrect data and outliers;

- DEA efficiency scores can be seriously influenced by the content of the sample (when adding each new object of analysis, it is necessary to recalculate the entire model);

- it provides information only about relative efficiency;

- DEA analysis is also more sensitive to data noise and measurement errors than parametric techniques like stochastic frontier analysis which allows for statistical noise.

The main idea of this linear programming model is to have a score between 0 and 1 representing the degree of efficiency of a DMU. When a DMU is technically efficient, it operates on the efficiency frontier and has an efficiency score of 1 . DMUs with efficiency scores less than one are considered to be inefficient. In the DEA approach, the performance of each DMU is measured relative to the performance of all other DMUs. DEA provides information about the relatively best practice DMUs in the observation set and identifies the relatively inefficient DMUs by comparison with the best practice ones. As mentioned by Al-Shammari (1999), besides, it identifies the magnitude of these inefficiencies and helps to understand the ways to improve them. Such units (DMUs) can represent units in healthcare as hospitals (Al-Shammari, 1999; Jacobs, 2001; Özcan, 2008; Ahmed et al., 2019), or different units within hospitals (Wang \& Yu, 2006; Akkan et al., 2019), provinces and regions (Kocisova, Hass-Symotiuk, \& Kludacz-Alessandri, 2018; Stefko, Gavurova, \& Korony, 2016) as well as countries (Afonso \& St. Aubyn, 2005; Borisov \& Cicea, 2012; Reinhardt \& Hussey, 2002). Thus, DEA is a beneficial technique for healthcare administrators seeking to identify opportunities for performance improvement.

The goal of measuring the efficiency of healthcare delivery using DEA is complicated and can be realised by using multiple inputs and multiple outputs in calculations. In many studies regarding healthcare systems efficiency, the inputs were measured by expenditure on health per capita (Spinks, \& Hollingsworth, 2009), or by the number of various healthcare resources like a number of inpatient beds, the number of bed days, total 
full-time and part-time staff (e.g. Al-Shammari, 1999; Afonso \& St. Aubyn, 2005; Bhat, 2005), the operational expenses, not including payroll, capital or depreciation expenses, total assets (Nayar \& Ozcan, 2008), consumption of fruit and vegetables per capita (Hadad et al., 2013), pharmaceutical consumptions (Bhat, 2005), or average length of stay. However, as mentioned by Moran and Jacobs (2013), the average length of stay is often seen as an essential quality indicator which may be associated with health outcomes.

There are different opinions in the literature on which variables should be considered as good health outcomes (Richardson, Wildman, \& Robertson, 2003; Williams, 2003). The quantity output variables often included in DEA models are number of patient days, number of minor operations, and number of significant operations (Al-Shammari, 1999); total outpatient visits (all visits to hospital emergency and outpatient facilities), and training full-time equivalents (Nayar \& Ozcan, 2008). There are not many studies in the literature that include qualitative variables as outputs in DEA analyses, especially in the literature regarding the healthcare sector. According to Ikegami, Hirdes and Carpenter (2002), one of the possible reasons of such situation could be the problem with the access to the validated measures of quality and the lack of a composite measure to evaluate the overall quality of the healthcare delivery. In many studies, the healthcare quality outcomes are measured by mortality and survival rates, or life expectancy at birth (Retzlaff-Roberts et al., 2004; Mohan \& Mirmirani, 2007; Spinks \& Hollingsworth, 2009). Another critical quality outcomes of the healthcare system taken into account in the past research are recovery and readmission rates.

A key component of health sector efforts to improve operating efficiency has to do with making the best use of existing resources. The costs of healthcare are a growing concern for many governments in the world. According to Wilkins et al. (2017), on an EU basis, $51 \%$ of total healthcare expenditure on CVD patients are directed towards inpatient care. Most countries which collect data on the efficiency of healthcare delivery, tend to focus on measures of resource utilisation concerning hospital care because this care is responsible for the use of the significant amount of resources in the healthcare system. Total healthcare costs, therefore, play a significant role in most of the efficiency indicators. If providers can reduce costs to the level of best practice, the resources might be released to provide benefits elsewhere. As mentioned by Bhat (2005), the problem with using costs to measure effectiveness in cross-countries analyses is that healthcare expenditures are difficult to interpret across countries as they are measured in different currencies with vastly different spending powers. The other problem is that cost savings could be a result of selections or reductions in the quality of care. In the time of cost limitations and resource constraints, the healthcare systems are facing incentives to improve technical efficiency that results in optimal resource utilisation.

On the other hand, the emphasis on the quality of healthcare by patients and other stakeholders in healthcare systems is also increasing. In recent years, the imperative of quality has been strongly influencing health institutions. There is a discussion in the literature if it is possible to be focused on improving quality outcomes while stressing the importance of technical efficiency. In such cases, it is interesting to examine if healthcare systems focused on technical efficiency are compromising their quality.

Maximising health system performance requires a complete understanding of its determinants. Most significant determinants are connected with health expenditure and other health resources. There is also a body of literature suggesting that the comparative efficiency analyses should explore not only endogenous but also exogenous factors that may impact on health system performance (Moran \& Jacobs, 2013; Anand et al., 2016). For instance, very often analysed are socioeconomic determinants, such as unemployment rate, education attainment, GDP per capita (Economou \& Giorno, 2009; Schwellnus, 2009; Spinks \& Hollingsworth, 2009) and environmental variables regarding the social environment, population lifestyles, attitudes and health-related behaviours (Retzlaff-Roberts, Chang, \& Rubin, 2004). Among the most popular health-related factors that can affect efficiency include alcohol consumption, oil consumption, physical activity, age structure, tobacco consumption (Bhat, 2005). For instance, in the study of RetzlaffRoberts et al. (2004), the environmental 
variables included the maximum value of the percentage of male and female smokers.

\section{Methodology}

This section introduces the fundamental principles of the DEA as a productivity analysis tool for the healthcare sector in OECD countries. Single efficiency scores have been calculated and compared using OECD countries as decision-making units (DMU). This model provides the efficiency score in the presence of multiple input and output factors defined as:

$$
\text { Efficiency }=\frac{\text { weighted sum of outputs }}{\text { weighted sum of inputs }}
$$

Assuming that there are $n$ DMUs, each uses $m$ inputs and to produces $s$ outputs, the relative efficiency score of a DMU $p$ is obtained by solving the following model proposed by Charnes et al. (1978):

$$
\begin{aligned}
& \max \frac{\sum_{k=1}^{S} v_{k} y_{k p}}{\sum_{j=1}^{m} u_{j} x_{j p}} \\
& \text { s.t. } \quad \frac{\sum_{k=1}^{S} v_{k} y_{k i}}{\sum_{j=1}^{m} u_{j} x_{j i}} \leq 1 \forall_{i} \\
& v_{k} u_{j} \geq 0 \forall_{k, j}
\end{aligned}
$$

where: $k=1$ to $s ; j=1$ to $m ; i=1$ to $n$; $y_{k i}=$ amount of output $k$ produced by DMU $i$; $\mathrm{x}_{j i}=$ amount of input $\mathrm{j}$ utilised by DMU $i$; $v_{\mathrm{k}}=$ weight given to output $k$; $u_{j}=$ weight given to input $j$.

The fractional program shown as (2) and (3) can be converted to a linear program, as shown in (4) and (5). For more details about the model, see Charnes et al. (1978).

$$
\begin{aligned}
& \max \sum_{k=1}^{S} v_{k} y_{k p} \\
& \text { s.t. } \sum_{j=1}^{m} u_{j} x_{j p}=1 \\
& \sum_{k=1}^{s} v_{k} y_{k i}-\sum_{j=1}^{m} u_{j} x_{j i} \leq 0 \forall_{i} \\
& v_{k}, u_{j} \geq 0 \forall_{k, j}
\end{aligned}
$$

The above problem is performed $n$ times to identify the relative efficiency scores of all the DMUs. Each DMU selects input and output weights that maximise its efficiency score. Generally, a DMU is considered as efficient if it obtains a score of 1 , and a score of fewer than 1 means it is inefficient. We used Data Envelopment Analysis Program (version 2.1) to examine the data. In our study, we used constant returns to scale (CRS) input-oriented models.

One of the essential steps in DEA is to set up input and output variables. The definitions of input variables used in this study are presented in Tab. 1. These input variables are consistent with the DEA literature. The model containing the quantitative inputs was also specified in the study of Arocena and García-Prado (2007). The authors considered four inputs: labour (physicians and nurses), equipment (beds) and expenditure on goods and services. All variables were measured in physical units, except for expenditure in goods and services, which was expressed in constant monetary units. Also, Afonso and St. Aubyn (2005) used a number of physicians, nurses and beds per 1,000 population as an input variable in the analysis of efficiency of OECD countries. In the study of Retzlaff-Roberts et al. (2004) healthcarerelated inputs variables included the number of physicians, beds, Magnetic Resonance Imaging units per million population and also healthcare expenditure as a percentage of GDP. The use of medical technologies (number of all medical equipment, number of magnetic resonance devices, number of computed tomography devices) was also used as inputs to assess the efficiency of the healthcare facilities and their adequacy in the evaluation of the monitored processes in Slovakian regions realised by Stefko et al. (2018). According to Greene (2004), health expenditure (per capita) is a significant component of healthcare system performance and should also be taken into account as an input measure.

The definitions of output variables used in this study are presented in the following table (Tab. 2). These output variables are consistent with the output variables used in the DEA literature. The model containing the outputs based on the quantitative and quality indicators was also specified in the study of Arocena and García-Prado (2007). The authors incorporated into the calculation of efficiency scores the following variables: the number of discharges and outpatient hospital services 


\section{Tab. 1: Definition of input variables included in the DEA models}

\begin{tabular}{l|l|l}
\multicolumn{1}{c|}{ Input variable } & \multicolumn{1}{c|}{ Acronym } & \multicolumn{1}{c}{ Definition } \\
\hline Cardiologists & CARD & $\begin{array}{l}\text { Number of practising, professionally active or licensed to } \\
\text { practice cardiologists per 100,000 inhabitants; 2015 }\end{array}$ \\
\hline $\begin{array}{l}\text { Angiography } \\
\text { equipment }\end{array}$ & ANG & Number of angiography equipment per 100,000 inhabitants; 2015 \\
\hline $\begin{array}{l}\text { Total healthcare } \\
\text { costs of CVD }\end{array}$ & TCOST & $\begin{array}{l}\text { Total healthcare costs of CVD patients per 100,000 inhabitants; } \\
2015 \text { (thousands of EUR) }\end{array}$ \\
\hline
\end{tabular}

Source: Wilkins et al. (2017); EUROSTAT (2015)

as representative of quantitative outputs and hospital 're-admissions' as representative of 'quality' in the form of undesirable output. Adjusted discharges (total hospitals inpatient discharges) were also used as output variables in the study of Nayar and Ozcan (2008) for comparison of hospital efficiency among Virginia hospitals. Surgical operations are also popular output measure in the literature regarding healthcare system efficiency (Ersoy, Kavuncubasi, Ozcan, \& Harris, 1997; Gok \& Sezen, 2013; Sezen \& Gok, 2016; Stancheva \& Angelova, 2004). In our study, we took into account surgical operations and procedures performed related to disease of the circulatory system (per 100,000 inhabitants), which are available for providing services to CVD patients in hospitals. We took into account transluminal coronary angioplasty, bypass anastomosis for heart revascularization, carotid endarterectomy, femoropopliteal bypass.

The quality variables connected with mortality and survival rates are consistent with the DEA literature. They are the most commonly used outcome variables. The patient deaths as undesirable outputs were already used by Yawe and Kavuma (2008) to measure hospital technical efficiency for a sample of Uganda's district referral hospitals using Data Envelopment Analysis. According to the authors, the death of a patient in the course of administering treatment is a negative side effect of health processes in the hospital. They treat patient deaths as undesirable outputs which inclusion into the efficiency evaluation is essential for providing a real picture of the technical efficiency of a decision-making unit. Hospitals and other healthcare institutions seek to minimise such undesirable outputs because one of their overriding objectives is to improve the health status of the patients or save their lives. According to Nayar and Ozcan (2008), the problem with using mortality rates as output measure of quality is a concern that hospital treating the sickest patients may be unfairly labelled as inefficient as compared to their peers. However, this problem does not concern the country level. As mentioned by Hadad et al. (2013), the DEA technique implies that outputs are measured in such a way that "more is better". Since the infant mortality rate (IMR) does not meet this rationale, we have

\section{Tab. 2: Definition of output variables included in the DEA models}

\begin{tabular}{l|l|l}
\multicolumn{1}{c|}{ Output variable } & Acronym & \multicolumn{1}{c}{ Definition } \\
\hline Surgical operations & SURG & $\begin{array}{l}\text { Surgical operations and procedures performed in hospitals } \\
\text { related to disease of the circulatory system (per 100,000 } \\
\text { inhabitants); 2015 }\end{array}$ \\
\hline Discharge rates & DISCHARGE & $\begin{array}{l}\text { Hospital discharge rates for in-patients with diseases of the } \\
\text { circulatory system; 2015 }\end{array}$ \\
\hline $\begin{array}{l}\text { Standardised survival } \\
\text { rate }\end{array}$ & SURV & $\begin{array}{l}\text { Standardised survival rates related to diseases of the } \\
\text { circulatory system per 100,000 inhabitants; 2015 }\end{array}$ \\
\hline
\end{tabular}


calculated the survival rate (SURV) as follows: SURV $=(1-I M R) / 100,000$. This indicator is also well accepted as a quality health indicator.

This study focuses explicitly on comparing two dimensions of hospital performance: technical efficiency based on quantitative outputs (TE) and technical efficiency based on quality outputs (QE). The frontier analysis is therefore carried out on cross-sectional data for 2015 using two alternative models in terms of model assumptions. The following DEA models were examined (Tab. 3):

- Model 1 (TE): a model of technical efficiency involves two quantitative outputs and three inputs. The inputs used in this model were the number of cardiologists, number of angiography equipment and total healthcare costs of CVD patients. The quantitative outputs used in the model were: surgical operations and procedures and hospital discharge rates related to cardiovascular diseases.

- Model 2 (QE): a model of technical efficiency involves one quality output and three inputs. The quality output used in the model was standardised survival rates of patients with cardiovascular diseases. The inputs used were the same as in model TE.

Similar QE model was used by Afonso and St. Aubyn (2005) who used a number of physicians, nurses and beds per 1000 population as input variables and infant survival rate (ISR) and life expectancy (LE) at birth as output variables. Also, Varabyova and Schreyögg (2013) analysed the hospital care efficiency in OECD countries using similar
DEA models considering hospital discharges and mortality as output variables. In contrast, hospital resources such as a number of beds, physicians, nurses and hospital employments were the inputs.

We also control for potential environmental factors that may impact on countries' efficiency, such as health-behaviour factors. Explanatory variables included in these analyses are defined in Tab. 4.

Selected indicators representing health behaviour of the population were connected with the consumption of oils, fruits, vegetables, fishes and alcohol and also with physical activity. Consumption of fishes, fruit and vegetables per capita are commonly used indicators used as a determinant that has a profound effect on individuals' health (Hadad et al., 2013; Starfield, 1973). Alcohol consumption is included as a health-behaviour factor since it is particularly strongly associated with general health problems (Institute of Medicine, 2006). The problem with this measure is that it may fail to account for a particularly dangerous pattern of consumption, namely large quantities of alcohol at a single session.

The sample for this study covered 18 OECD countries, for which data were available. Data for this study were extracted from EUROSTAT Health Database and European Cardiovascular Disease Statistics 2017. We used data from the year 2015. Because the number of DMUs (18) exceeds the number of the combined total of inputs and outputs by at least twice, DEA can operate more powerfully (Drake \& Howcroft, 1994).

\section{Tab. 3: Model specifications}

\begin{tabular}{l|l|c|c}
\multicolumn{2}{c|}{ Variables $^{*}$} & TE & QE \\
\hline \multirow{4}{*}{ Inputs } & CARD & $\mathrm{X}$ & $\mathrm{X}$ \\
\cline { 2 - 4 } & ANG & $\mathrm{X}$ & $\mathrm{X}$ \\
\cline { 2 - 4 } & TCOST & $\mathrm{X}$ & $\mathrm{X}$ \\
\hline \multirow{4}{*}{ Outputs } & SURG & $\mathrm{X}$ & \\
\cline { 2 - 4 } & DISCHARGE & $\mathrm{X}$ & \\
\cline { 2 - 4 } & SURV & & $\mathrm{X}$ \\
\hline
\end{tabular}




\begin{tabular}{l|l|l} 
Tab. 4: & $\begin{array}{l}\text { Definition of independent variables included in the analysis of determinants } \\
\text { of the efficiency of healthcare delivery }\end{array}$ \\
\hline \multicolumn{1}{c}{ Independent variables } & \multicolumn{1}{c}{ Acronym } & \multicolumn{1}{c}{ Definition } \\
\hline Alcohol consumptions & ALC & $\begin{array}{l}\text { Alcohol consumption in litres of pure } \\
\text { alcohol per capita (15+ years) per year }\end{array}$ \\
\hline Oil crops consumptions & OILCROPSKG & Oil crops consumption in kg per capita per year \\
\hline $\begin{array}{l}\text { Vegetable oil } \\
\text { consumptions }\end{array}$ & VEGOILKG & Vegetable oil consumption in kg per capita per year \\
\hline Vegetable consumptions & VEG & Vegetable consumption in kg per capita per year \\
\hline Fruit consumptions & FRUIT & Fruit consumption in kg per capita per year \\
\hline Oil crops consumptions & OILCROPSKCAL & Oil crops consumption in kcal per capita per day \\
\hline $\begin{array}{l}\text { Vegetable oil } \\
\text { consumptions }\end{array}$ & VEGOILKCAL & $\begin{array}{l}\text { Vegetable oil consumption in kcal per capita } \\
\text { per day }\end{array}$ \\
\hline Fish consumption & FISHKG & Fish consumption in kg per capita per year \\
\hline Fish consumption & FISHKCAL & Fish consumption in kcal per capita per day \\
\hline Frequency of exercising & ACTIV & $\begin{array}{l}\text { Percentage of the population aged 15+ practising } \\
\text { exercises at least once a week }\end{array}$ \\
\hline $\begin{array}{l}\text { Inpatient CVD costs per } \\
100,000 \text { citizens }\end{array}$ & IPTCOST & $\begin{array}{l}\text { Costs of CVD inpatients per 100,000 } \\
\text { inhabitants (thousands of EUR) }\end{array}$ \\
\hline
\end{tabular}

Source: EUROSTAT (2015)

\begin{tabular}{|c|c|c|c|c|c|}
\hline Tab. 5: & $\begin{array}{l}\text { lum and } \\
\text { models }\end{array}$ & um value & althcare in & and outp & \\
\hline \multirow{2}{*}{ Variable } & \multirow{2}{*}{ Median } & \multicolumn{2}{|c|}{ Minimum } & \multicolumn{2}{|c|}{ Maximum } \\
\hline & & Value & Country & Value & Country \\
\hline CARD & 9.2 & 1.89 & Slovenia & 21.65 & Italy \\
\hline ANG & 1 & 0.36 & Romania & 1.58 & Luxembourg \\
\hline TCOST & $13,786.96$ & $5,724.87$ & Cyprus & $36,538.78$ & Germany \\
\hline SURG & 283.8 & 161.28 & Luxembourg & 508.08 & Spain \\
\hline DISCHARGE & 2,229 & 844.10 & Cyprus & $4,339.1$ & Lithuania \\
\hline SURV & $99,868.1$ & $99,653.40$ & Slovenia & 99,929 & Croatia \\
\hline
\end{tabular}

Source: own

Tab. 5 presents the maximum and minimum values for healthcare inputs and outputs that were incorporated in the efficiency calculation of 18 OECD countries. Although all of these countries are defined as developed. There are observed significant differences between them regarding the level of healthcare resources, expenditures, as well as health outcomes. Italy, Luxembourg and Germany have the highest scores of inputs while Slovenia, Romania and Cyprus have the lowest. On the other hand,
Spain, Lithuania, Croatia have the highest scores of outputs while Luxembourg, Cyprus and Slovenia have the lowest.

\section{Results}

The DEA efficiency scores across two alternative models for 18 OECD countries are presented in Tab. 6 . The value of 1 indicates that a country is located at the frontier. The lower the value, the farther the country is from the efficient frontier. The ranking of the countries is based on two 


\section{Business Administration and Management}

models: TE and QE. Estimates of healthcare efficiency indicate how well a country utilises its healthcare resources. The DEA results documented in Tab. 6 identified comparatively efficient best-practice countries (score $=1$ ) and relatively inefficient countries (score $<1$ ) in both models. The countries with efficiency scores of 1 are presented in bold in order to highlight efficient countries. As mentioned by Kocisova et al. (2018), efficiency scores less than one implies that these countries can improve their efficiency by improving outputs and/or decreasing inputs. The hospitals from efficient countries are using fewer inputs to produce the same amount of outputs (or higher amount) compared to hospitals from inefficient countries. Using the TE model, it was found that out of 18 DMUs, 6 DMUs were efficient (efficiency score $=1$ ) and 12 DMUs (efficiency score < 1) were inefficient. Using the QE model, the number of efficient DMUs was reduced to five countries, and the number of inefficient countries increased to 13 . It was found that all efficient DMUs in QE model had efficiency scores less than 1 in model TE; indicating that although they were not maximising efficiency in terms of quantitative outcomes, they were maximising their quality outcomes.

The distribution of the inefficient countries over efficiency scores ranged from 0.283 to 0.864 in model QE and from 0.333 to 0.885 in model QE. The outcomes anticipated as a result of the analysis include:

- Six highly effective countries with an efficiency score of 1 in the TE model: Estonia, Cyprus, Lithuania, Malta, Romania and Slovenia;

- Five highly effective countries with an efficiency score of 1 in the QE model: Belgium, Spain, France, Luxembourg and Portugal;

- No country with an efficiency score between 0.91 and 0.99 in both models;

Tab. 6: Efficiency estimation across two alternative model specification (year 2015)

\begin{tabular}{l|c|c|c|c}
\multicolumn{1}{c|}{ DMU } & TE & TE-rank & QE & QE-rank \\
\hline Belgium & 0.524 & 12 & $\mathbf{1 . 0 0 0}$ & $\mathbf{1}$ \\
\hline Czech Republic & 0.707 & 8 & 0.536 & 14 \\
\hline Germany & 0.864 & 7 & 0.675 & 8 \\
\hline Estonia & $\mathbf{1 . 0 0 0}$ & 1 & 0.567 & 11 \\
\hline Spain & 0.705 & 9 & $\mathbf{1 . 0 0 0}$ & $\mathbf{1}$ \\
\hline France & 0.475 & 15 & $\mathbf{1 . 0 0 0}$ & $\mathbf{1}$ \\
\hline Croatia & 0.591 & 11 & 0.540 & 13 \\
\hline Italy & 0.283 & 18 & 0.885 & 6 \\
\hline Cyprus & $\mathbf{1 . 0 0 0}$ & 1 & 0.660 & 9 \\
\hline Lithuania & $\mathbf{1 . 0 0 0}$ & 1 & 0.333 & 18 \\
\hline Luxembourg & 0.481 & 14 & $\mathbf{1 . 0 0 0}$ & $\mathbf{1}$ \\
\hline Malta & $\mathbf{1 . 0 0 0}$ & 1 & 0.550 & 12 \\
\hline Poland & 0.496 & 13 & 0.577 & 10 \\
\hline Portugal & 0.422 & 16 & $\mathbf{1 . 0 0 0}$ & $\mathbf{1}$ \\
\hline Romania & $\mathbf{1 . 0 0 0}$ & 1 & 0.468 & 17 \\
\hline Slovenia & $\mathbf{1 . 0 0 0}$ & 1 & 0.516 & 15 \\
\hline Finland & 0.622 & 10 & 0.502 & 16 \\
\hline Sweden & 0.408 & 17 & 0.691 & 7 \\
\hline
\end{tabular}


- Three countries with an efficiency score between 0.71 and 0.9 in model TE: Germany (0.864), the Czech Republic (0.707) and Spain (0.705);

- One country with an efficiency score between 0.71 and 0.9 in model QE: Italy (0.885);

- Three highly ineffective countries with an efficiency score between 0.51 and 0.7 in model TE: Belgium (0.524), Croatia (0.591) and Finland (0.622);

- Ten highly inefficient countries with an efficiency score between 0.51 and 0.70 in model QE: the Czech Republic (0.536), Germany (0.675), Estonia (0.567), Croatia (0.54), Cyprus (0.66), Malta (0.55), Poland (0.577), Slovenia (0.516), Finland (0.502) and Sweden (0.69);

- Six relatively most-inefficient countries with an efficiency score below 0.5 in model TE: France (0.47), Italy (0.283), Luxembourg (0.481), Poland (0.496), Portugal (0.422) and Sweden (0.408);

- Two relatively most-inefficient countries with an efficiency score below 0.5 in model QE: Lithuania (0.333) and Romania (0.468).

The relatively most inefficient country in TE model was Italy. The 0.283 efficiency score tells us that hospitals from efficient countries can obtain at least the level of each quantitative output that Italy obtains by having available no more than $28.3 \%$ of inputs required by hospitals from Italy. It also means that hospitals from Italy should be able to achieve its actual output level using, on average, about $71.78 \%$ less of each input. In the model QE, the lowest result was achieved by Lithuania (0.333). This efficiency score means that efficient countries can obtain at least the same level of quality output as Lithuania by having available $66.6 \%$ or fewer inputs. The DEA efficiency scores across two alternative models in OECD countries are also presented in Fig. 1.

All countries are highly sensitive to model specification, especially Italy, Spain, Lithuania, Luxembourg, Portugal, Romania. As it is presented in Tab. 6 and Fig. 1 countries which lie on the technical efficiency frontier in model TE (Estonia, Cyprus, Lithuania, Malta, Romania, Slovenia) perform worse on technical efficiency in model QE. We can see that some of the developed economies (e.g. Belgium, France, Luxembourg) are efficient in model QE and inefficient in model TE. In contrast, some of the developing economies (e.g. Romania, Lithuania, Estonia) are efficient in model TE and inefficient in model QE. None of the countries in the sample had a score of 1 in both DEA models.

\section{Fig. 1: Efficiency estimation across two alternative model specification (year 2015)}

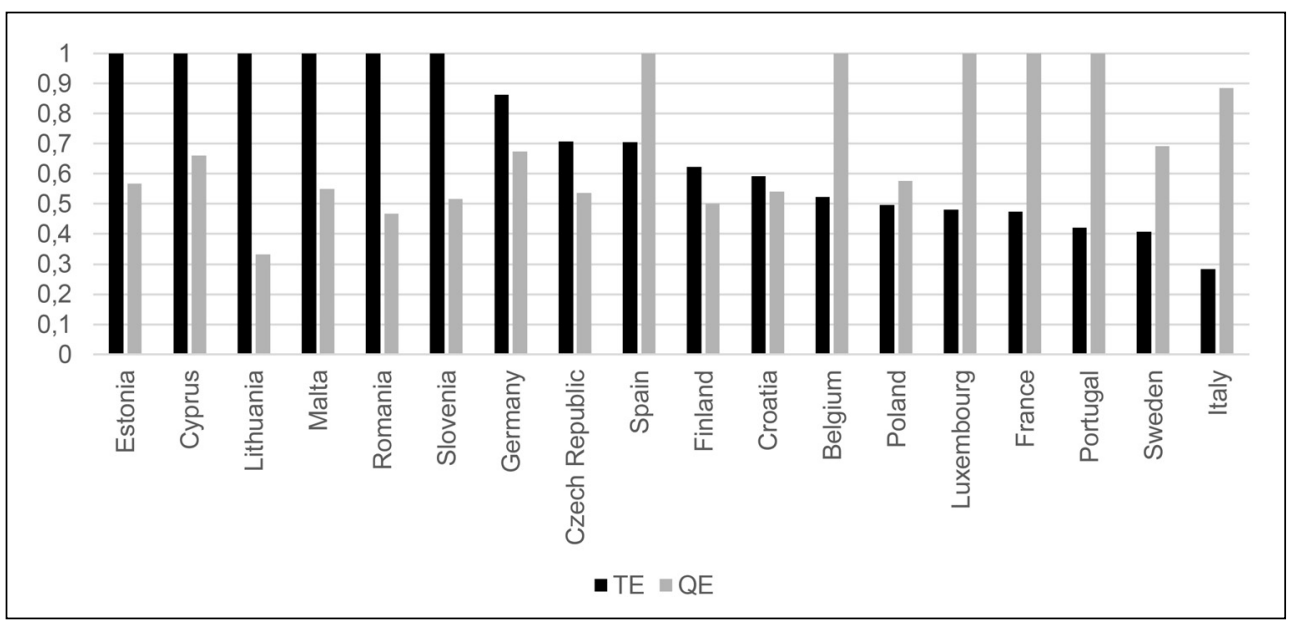

Note: TE - Technical efficiency, QE - Quality efficiency. 


\section{Business Administration and Management}

The results showed that the technical efficiency of healthcare delivery might be improved at the expense of quality. The comparison of technical efficiency in the TE model of the hospital industries across countries should, therefore, be critically considered as it concerns the use of resources and does not directly address health outcomes.

The DEA models defined in this paper make it possible to compare efficient and inefficient

Tab. 7: Input, output and explanatory variable comparison between efficient and inefficient healthcare systems for CVD patients - Part 1

\begin{tabular}{|c|c|c|c|c|c|c|}
\hline \multirow[b]{2}{*}{ Variable } & \multicolumn{3}{|c|}{$\begin{array}{l}\text { Model } 1 \\
\text { (TE) }\end{array}$} & \multicolumn{3}{|c|}{$\begin{array}{l}\text { Model } 2 \\
(Q E)\end{array}$} \\
\hline & $\begin{array}{l}\text { Efficient* } \\
\text { Mean } \\
\text { (SD) }\end{array}$ & $\begin{array}{c}\text { Inefficient } \\
\text { Mean } \\
\text { (SD) }\end{array}$ & P-value ${ }^{* * *}$ & $\begin{array}{c}\text { Efficient** } \\
\text { Mean } \\
\text { (SD) }\end{array}$ & $\begin{array}{c}\text { Inefficient } \\
\text { Mean } \\
\text { (SD) }\end{array}$ & P-value $* * *$ \\
\hline \multicolumn{7}{|c|}{ Input variables } \\
\hline CARD & $\begin{array}{l}10.93 \\
(7.09)\end{array}$ & $\begin{array}{c}10 \\
(4.07)\end{array}$ & Ns & $\begin{array}{c}9.67 \\
(7.14)\end{array}$ & $\begin{array}{l}10.56 \\
(4.38)\end{array}$ & Ns \\
\hline ANG & $\begin{array}{c}0.72 \\
(0.22)\end{array}$ & $\begin{array}{c}1.16 \\
(0.33)\end{array}$ & $<0.01$ & $\begin{array}{c}0.69 \\
(0.24)\end{array}$ & $\begin{array}{c}1.14 \\
(0.33)\end{array}$ & $<0.01$ \\
\hline TCOST & $\begin{array}{c}9997.34 \\
(2654.76)\end{array}$ & $\begin{array}{l}20827.05 \\
(9551.69)\end{array}$ & $<0.01$ & $\begin{array}{l}10446.45 \\
(2701.28)\end{array}$ & $\begin{array}{l}19821.26 \\
(9837.83)\end{array}$ & $<0.01$ \\
\hline \multicolumn{7}{|c|}{ Output variables } \\
\hline SURG & $\begin{array}{l}375 \\
(86)\end{array}$ & $\begin{array}{l}248 \\
(64)\end{array}$ & $<0.01$ & $\begin{array}{l}251 \\
(62)\end{array}$ & $\begin{array}{l}393 \\
(82)\end{array}$ & $<0.01$ \\
\hline DISCHARGE & $\begin{array}{c}2449 \\
(1223)\end{array}$ & $\begin{array}{l}2119 \\
(725) \\
\end{array}$ & Ns & $\begin{array}{l}2290 \\
(928)\end{array}$ & $\begin{array}{l}2071 \\
(893) \\
\end{array}$ & Ns \\
\hline SURV & $\begin{array}{c}99782 \\
(97) \\
\end{array}$ & $\begin{array}{c}99864 \\
(58) \\
\end{array}$ & $<0.01$ & $\begin{array}{c}99850 \\
(75) \\
\end{array}$ & $\begin{array}{c}99802 \\
(94) \\
\end{array}$ & $<0.01$ \\
\hline \multicolumn{7}{|c|}{ Explanatory variables - health-related behaviour } \\
\hline ALC & $\begin{array}{c}11 \\
(2) \\
\end{array}$ & $\begin{array}{r}10 \\
(2) \\
\end{array}$ & Ns & $\begin{array}{c}11 \\
(2) \\
\end{array}$ & $\begin{array}{r}10 \\
(1) \\
\end{array}$ & Ns \\
\hline OILCROPSKG & $\begin{array}{c}5 \\
(5) \\
\end{array}$ & $\begin{array}{c}4 \\
(2) \\
\end{array}$ & Ns & $\begin{array}{c}4 \\
(2) \\
\end{array}$ & $\begin{array}{c}6 \\
(5) \\
\end{array}$ & Ns \\
\hline VEGOILKG & $\begin{array}{c}23 \\
(29) \\
\end{array}$ & $\begin{array}{r}19 \\
(6) \\
\end{array}$ & Ns & $\begin{array}{l}18 \\
(6) \\
\end{array}$ & $\begin{array}{c}26 \\
(31) \\
\end{array}$ & Ns \\
\hline VEG & $\begin{array}{l}137 \\
(43) \\
\end{array}$ & $\begin{array}{l}106 \\
(24) \\
\end{array}$ & Ns & $\begin{array}{l}107 \\
(23) \\
\end{array}$ & $\begin{array}{l}142 \\
(46) \\
\end{array}$ & Ns \\
\hline FRUIT & $\begin{array}{c}72 \\
(13)\end{array}$ & $\begin{array}{l}106 \\
(40)\end{array}$ & Ns & $\begin{array}{l}101 \\
(41)\end{array}$ & $\begin{array}{l}77 \\
(8)\end{array}$ & Ns \\
\hline OILCROPSKCAL & $\begin{array}{c}28 \\
(18)\end{array}$ & $\begin{array}{c}26 \\
(13)\end{array}$ & Ns & $\begin{array}{c}25 \\
(13)\end{array}$ & $\begin{array}{c}30 \\
(19)\end{array}$ & $\mathrm{Ns}$ \\
\hline VEGOILKCAL & $\begin{array}{l}279 \\
(98) \\
\end{array}$ & $\begin{array}{c}443 \\
(139) \\
\end{array}$ & $<0.01$ & $\begin{array}{c}423 \\
(151) \\
\end{array}$ & $\begin{array}{l}297 \\
(97) \\
\end{array}$ & $<0.01$ \\
\hline FISHKG & $\begin{array}{c}22 \\
(14) \\
\end{array}$ & $\begin{array}{c}28 \\
(14) \\
\end{array}$ & Ns & $\begin{array}{c}29 \\
(14) \\
\end{array}$ & $\begin{array}{c}17 \\
(10) \\
\end{array}$ & Ns \\
\hline FISHKCAL & $\begin{array}{c}46 \\
(39) \\
\end{array}$ & $\begin{array}{c}54 \\
(21) \\
\end{array}$ & Ns & $\begin{array}{c}58 \\
(26) \\
\end{array}$ & $\begin{array}{c}33 \\
(22) \\
\end{array}$ & Ns \\
\hline ACTIV & $\begin{array}{c}34 \\
(12)\end{array}$ & $\begin{array}{c}44 \\
(14)\end{array}$ & Ns & $\begin{array}{c}43 \\
(13)\end{array}$ & $\begin{array}{c}33 \\
(13)\end{array}$ & Ns \\
\hline
\end{tabular}




\begin{tabular}{|c|c|c|c|c|c|c|}
\hline Tab. 7: & $\begin{array}{l}\text { Itput and } \\
\text { ficient hea }\end{array}$ & $\begin{array}{l}\text { planatory } \\
\text { hcare syste }\end{array}$ & $\begin{array}{l}\text { iriable com } \\
\text { ns for CVD }\end{array}$ & $\begin{array}{l}\text { arison bety } \\
\text { atients }-P\end{array}$ & $\begin{array}{l}\text { een efficien } \\
\text { rt } 2\end{array}$ & \\
\hline \multirow[b]{2}{*}{ Variable } & \multicolumn{3}{|c|}{$\begin{array}{c}\text { Model } 1 \\
\text { (TE) }\end{array}$} & \multicolumn{3}{|c|}{$\begin{array}{c}\text { Model } 2 \\
\text { (QE) }\end{array}$} \\
\hline & $\begin{array}{c}\text { Efficient* } \\
\text { Mean } \\
\text { (SD) }\end{array}$ & $\begin{array}{c}\text { Inefficient } \\
\text { Mean } \\
\text { (SD) }\end{array}$ & P-value ${ }^{\star * *}$ & $\begin{array}{c}\text { Efficient** } \\
\text { Mean } \\
\text { (SD) }\end{array}$ & $\begin{array}{l}\text { Inefficient } \\
\text { Mean } \\
\text { (SD) }\end{array}$ & P-value ${ }^{* * *}$ \\
\hline \multicolumn{7}{|c|}{ Explanatory variables - other } \\
\hline INPAT $_{\mathrm{CVD}}$ & $\begin{array}{c}132478 \\
(220494)\end{array}$ & $\begin{array}{c}667432 \\
(878588)\end{array}$ & $<0.01$ & $\begin{array}{c}625787 \\
(854480)\end{array}$ & $\begin{array}{c}133764 \\
(246495)\end{array}$ & $<0.01$ \\
\hline $\mathrm{CITIZ} \mathrm{CVD}_{\mathrm{C}}$ & $\begin{array}{c}133039 \\
(221033)\end{array}$ & $\begin{array}{c}676192 \\
(867197)\end{array}$ & $<0.01$ & $\begin{array}{c}633927 \\
(844146)\end{array}$ & $\begin{array}{c}134295 \\
(247098)\end{array}$ & $<0.01$ \\
\hline IPTCOS $_{\mathrm{T} 100,000}$ & $\begin{array}{c}1986 \\
(1415)\end{array}$ & $\begin{array}{c}6206 \\
(4682)\end{array}$ & Ns & $\begin{array}{c}5786 \\
(4731)\end{array}$ & $\begin{array}{c}2232 \\
(1431)\end{array}$ & $<0.01$ \\
\hline
\end{tabular}

Source: own

Note: * A country's healthcare delivery for CVD patients was defined efficient when its technical efficiency score (TE) equalled 1; otherwise it was defined as inefficient;

** A country's healthcare delivery for CVD patients was defined efficient when its quality efficiency score (QE) equalled 1; otherwise, it was defined as inefficient;

*** Statistical significance calculated with Mann-Whitney test.

healthcare delivery for CVD patients in terms of healthcare resources, health-related behaviour (e.g. eating habits), costs dedicated to CVD patients and health outcomes. Tab. 7 contains descriptive statistics for the input, output and explanatory variables for efficient and inefficient countries in both models. The differences between the two samples (efficient and inefficient units under each model separately) were tested using the Mann-Whitney test. A p-value of less than 0.05 was considered statistically significant. The Mann-Whitney test can be used to compare differences between two independent groups when the dependent variable is either ordinal or continuous, but not normally distributed. We want to understand whether explanatory variables differed based on efficiency score.

The average inputs for the efficient countries in the model TE were 10.93 cardiologists per 100,000 inhabitants, 0.72 angiography equipment per 100,000 inhabitants and 9,997.34 thousand of EUR total healthcare costs of CVD. The average outputs produced by hospitals in the efficient countries were 375 surgical operations and procedures performed in hospitals related to disease of the circulatory system (per 100,000 inhabitants), 2,449 hospital discharge rates for in-patients with diseases of the circulatory system (per 100,000 inhabitants), and 99,782 standardised survival rates related to diseases of the circulatory system (per 100,000 inhabitants). The average inputs for the inefficient hospitals in the model TE were ten cardiologists per 100,000 inhabitants, 1.16 angiography equipment per 100,000 inhabitants and 20,827.05 thousand of EUR total healthcare costs of CVD. The average outputs produced by hospitals from the inefficient countries were 248 surgical operations and procedures related to disease of the circulatory system (per 100,000 inhabitants), 2,119 hospital discharge rates for in-patients with diseases of the circulatory system (per 100,000 inhabitants), and 99,864 standardised survival rates related to diseases of the circulatory system (per 100,000 inhabitants).

The average inputs for the efficient hospitals in the model QE were 9.67 cardiologists per 100,000 inhabitants, 0.69 angiography equipment per 100,000 inhabitants and $10,446.45$ total healthcare costs of CVD. The average outputs produced by hospitals in the efficient countries were 251 surgical operations and procedures performed in hospitals related 
to disease of the circulatory system (per 100,000 inhabitants), 2,290 hospital discharge rates for in-patients with diseases of the circulatory system (per 100,000 inhabitants), and 99,802 standardised survival rates related to diseases of the circulatory system (per 100,000 inhabitants). The average inputs for the inefficient hospitals in the model QE were 10.56 cardiologists per 100,000 inhabitants, 1.14 angiography equipment per 100,000 inhabitants and 19,821.26 thousand of EUR total healthcare costs of CVD. The average outputs produced by hospitals from the inefficient countries were 293 surgical operations and procedures performed in hospitals related to disease of the circulatory system (per 100,000 inhabitants), 2,071 hospital discharge rates for in-patients with diseases of the circulatory system (per 100,000 inhabitants), and 99,802 standardised survival rates related to diseases of the circulatory system (per 100,000 inhabitants).

Among input variables, only the total healthcare costs of CVD were found to be associated with countries' healthcare systems' efficiency. In model TE, it was found that with the increase in the total healthcare costs, their healthcare systems' efficiency decreased. According to model QE, these costs were significantly higher among countries with efficient healthcare systems. As to healthcare resources, interestingly, the number of cardiologists was not found to be associated with the healthcare system's efficiency according to both models. Differences between effective and ineffective health care systems were statistically insignificant.

As to outputs, discharges were not found to be significantly associated with the countries' healthcare systems' efficiency, although efficient healthcare systems according to both models were characterised by a higher number of surgical operations and lower survival rate in model TE and a lower number of surgical operations and higher survival rate in model QE.

The means and standard deviations reported in the table suggest that there are substantial variations across the efficient and inefficient samples in analysed models concerning the inpatient total CVD costs per 100,000 citizens. Most variables representing health-related behaviours were not considered determinants affecting the healthcare system's efficiency in both models. Only significantly higher consumption of vegetable oils was observed in the efficient healthcare systems according to model QE (423 vs 297). On the other hand, the efficient healthcare systems, according to model TE, were characterised by significantly lower consumption of vegetable oils (279 vs 443$)$.

\section{Discussion}

We examined the use of two model approaches to explore relative efficiency on available data, namely TE model based on quantitative output variables and $Q E$ model based on quality output variables. We examined whether these models produce complementary results in categorising countries in terms of broad patterns of efficiency. In the end, we used critical healthbehaviours factors to check if they impact technical efficiency in both models.

The most significant finding of the analysis of the DEA models was that DMUs that were efficiently producing quantitative outputs (surgical operations, hospital discharge rates) were inefficient in producing the quality outputs (survival rates). None of the DMUs in the sample had a score of 1 in both DEA models (TE and QE). The results from the two DEA models revealed that countries defined as efficient in terms of quantitative outputs were found to be inefficient in terms of quality (survival of these patients). It indicates that the DMUs were behaving as only quantity or only quality maximising units - this support other results providing evidence for quantitative/ qualitative efficiency trade-off (Mitropoulos, 2019). Even though developed countries (France, Spain, Luxembourg, Portugal, Belgium) are not efficient when quantitative outputs are considered, these countries can be followed as the model countries for most of the inefficient countries in the QE model, when the survival rate is considered as output. The results from the two DEA models revealed that these healthcare systems were defined as efficient when the assessment of health delivery for CVD patients relied on quality outputs connected with survival rate but was found to be inefficient when the assessment relied on quantitative outputs connected with the discharges and surgical operations. The following discussion considers the results in light of the currently available literature.

There have been already studies using productive and quality variables in DEA models to evaluate the effectiveness of healthcare 
delivery. For instance, Mitropoulos (2019) has explored whether there is a trade-off between service production and service quality in the healthcare delivery process also at a country level and he has revealed that the efficiency gains of several countries were achieved either by sacrificing production or quality. The study of the association between productivity and quality indicators was also the purpose of the study of Navarro-Espigares and Torres, (2011) who conducted an analysis in the Andalusian Hospitals and observed a weak association between efficiency based on productive and quality indicators and ruled out the existence of an efficiency/quality trade-off. Other authors conducted efficiency analysis in long term care units using measures of clinical quality, and they did not find a systematic association between technical efficiency and clinical quality of care except some dimensions of quality (depression medication and treatment) that were significantly associated with technical efficiency (Laine, Linna, Häkkinen, \& Noro, 2005). The other results (e.g. Nayar \& Ozcan, 2008) showed that the hospitals that were efficient in producing quantitative outputs (e.g. outpatient visits, adjusted discharges) were also efficient in producing the quality outputs (quality measures as a per cent of pneumonia patients receiving oxygenation assessment, initial antibiotic timing and pneumococcal vaccination).

The results regarding the relationship between quality and technical efficiency in the healthcare sector depend on the approach to quality which encompasses several aspects and performance dimensions such as accessibility, safety, health outcomes, patient-centeredness. As mentioned by Navarro-Espigares and Torres (2011), there are also opinions that various types of conditions influence the relationship between quality and technical efficiency in the healthcare sector. It is crucial to connect the objectives of quality and technical efficiency in order to effectively satisfy the needs of patients and various stakeholders functioning in the healthcare system. They should be considered as complementary, not mutually exclusive alternatives.

It is essential to ensure that an assessment of best practice includes not only costs but also patient outcomes. Our results showed that high costs might be associated with better quality outcomes and not only with inefficiency. On the other hand, low costs may be associated with low-quality care leading to poor quality outcomes. Our results illuminate the importance of ensuring adequate medical care on rather than focusing only on reducing expenditures and other healthcare resources in order to improve efficiency based on quantitative output variables. The fact that the use of resources does not directly address quality has been already noticed in previous studies (e.g. Varabyova \& Schreyögg, 2013). In our study total healthcare costs of CVD and inpatient total CVD costs per 100,000 citizens were found to be associated with countries' healthcare systems' efficiency, but according to model QE, these costs were significantly higher among countries with efficient healthcare systems. For instance, although Germany ranks seventh (in TE model) or eighth (in QE model) among the 18 countries, it has the highest (per capita) healthcare expenditures. It means that even if Germany spends more on healthcare than any other country, we cannot assume that there is an inefficient healthcare delivery system. Germany is more efficient than many other countries if other inputs/outputs are considered. It shows that health expenditure is a poor indicator of the performance of a healthcare delivery system of a country. Also, according to Bhat (2005), healthcare efficiency may not be directly related to the health expenditures (in absolute terms and as a proportion of gross domestic product) because prices of inputs differ across countries. Also, Hofmarcher and Smith (2013) pointed to the fact that information on healthcare costs and health expenditure is often limited in scope and comparability, and healthcare expenditure data by the disease are often particularly challenging to obtain for research purposes.

We did not confirm that health-related behaviour is associated with higher technical (TE) or quality (QE) efficiency healthcare systems in the field of CVD. Also, in the study of Bhat (2005) alcohol consumption (in litters) per population aged 15 years, or over did not show statistically significant association with technical efficiency in OECD countries. The author found that a factor that contributes significantly to ill health is tobacco use. Increased smoking is associated with higher levels of premature mortality. Since countries with a higher smoking rate are likely to require higher input resources, they should be less efficient. On the other hand, there is robust evidence that unhealthy 
behaviour (such as a low level of leisure physical activity and heavy alcohol use) is associated with increased death risks (Ezzati, Lopez, Rodgers, Vander Hoon, \& Murray, 2002; Kujala, Kaprio, \& Koskenvuo, 2002; Laaksonen et al., 2001). Other authors also suggest that a nation that is directed to improve its population's health should encourage healthy behaviours (e.g. Isaacs \& Schroeder, 2004).

Further research using validated outcome variables of quality is required to see if these preliminary findings are consistent. According to Al-Shammari (1999), the quality output variables should also include the level of intensity of hospital procedures and operations. For instance, in the literature, it has been proved that case-mix differences have an essential impact on resource consumption (Sharkey, Dehaemer, \& Horn, 1993).

\section{Conclusion}

This research aims to provide an evaluation of healthcare system efficiency of 18 OECD countries. Our study estimated the efficiency of healthcare delivery for CVD patients using two separate DEA models. The first included two quantitative outputs (discharges and surgical operations), and the second one included one quality output (survival rate). The two quantitative output variables we use in the first model TE, discharges and surgical operations, and one quality variable we use in the second model QE (survival rate) is generally accepted measures as system output in the literature. To the best of our knowledge, this is the first study that suggests using two different DEA models for evaluating the efficiency of healthcare delivery for CVD patients at the country level.

In this study, the DEA results provided the efficiency ranking of OECD countries in terms of healthcare delivery for CVD patients. Some countries appear to be relatively efficient, but many of those not on the efficiency frontier are far to it, with efficiency scores less than 0.5.

Our analysis can be summarised in five results: (1) The healthcare delivery for CVD patients were defined as efficient in terms of quality in five countries with large and stable economies, but was found to be inefficient in terms of productivity, (2) The healthcare delivery for CVD patients were defined as efficient in terms of productivity in six countries mainly from Central and Eastern Europe but was found to be inefficient in terms of quality.
(3) Inefficient countries in TE model have higher total expenditures than efficient countries. On the other hand countries with higher total costs have higher efficiency in QE model. These countries have a better survival rate even if they are less efficient in terms of productivity (less surgical operations). (4) Countries that are efficient concerning quantitative variables but are inefficient concerning survival rates from CVD causes of death should focus on the significant causes of death of CVD patients in order to improve their standing. (5) Most variables representing health-related behaviours were not considered determinants affecting the healthcare system's efficiency in both models.

The fact that the healthcare systems with higher inputs (number of cardiologists and healthcare expenditures) were defined as efficient by the QE model, and inefficient by the TE model, means that the pressure on resource optimisation, especially expenditure reduction does not allow to focus on ensuring adequate medical care which results in lower survival rate. We agree with the results of Pai, Hosseini and Brown (2019) suggesting that hospital managers should focus more on quality of care and less on cost reduction and technical efficiency.

As mentioned by Hadad et al. (2013), the DEA analysis provides countries whose healthcare systems are inefficient with useful information regarding the ability to improve their health outcomes by utilising inputs more efficiently. This study represents a significant contribution to the DEA literature as few previous studies have analysed the technical efficiency of healthcare delivery for CVD patients taking into account output variables related to productivity and quality. It also has implications for policy because the findings indicate that a focus on improving technical efficiency that is based on productivity outcomes is likely to compromise technical efficiency that is based on quality outcomes. The findings of this study are especially significant for policymakers and administrators alike, as the evidence is that hospitals can maximise quality without increasing quantity; and productivity can be at the expense of quality. The inclusion of quality output variables in DEA offers promise as a benchmarking tool for hospitals.

The main limitation of the study is that the efficiency was calculated for only one year. 
It was because the information concerning the costs of CVD inpatients in Europe is not measured and published systematically. The most recent data are from 2015.

Acknowledgement: This research was funded by the Slovak Research and Development Agency under contract No. APVV-17-0360: Multidimensional analysis of significant determinants of public procurement efficiency with emphasis on the application of Health Technology Assessment in the procurement preparation phase and by research project VEGA 1/0794/18: Development of a methodological platform for evaluation of efficiency in the financial and non-financial sector.

\section{References}

Adang, E. M. M., Gerritsma, A., Nouwens, E., van Lieshout, J., \& Wensing, M. (2016). Efficiency of the implementation of cardiovascular risk management in primary care practices: An observational study. Implementation Science, 11(1), 1-7. https://doi. org/10.1186/S13012-016-0434-2

Afonso, A., \& St. Aubyn, M. (2005). Nonparametric approaches to education and health efficiency in OECD countries. Journal of Applied Economics, 8(2), 227-246. https://doi.org/10.1 080/15140326.2005.12040626

Ahmed, S., Hasan, M. Z., Laokri, S., Jannat, Z., Ahmed, M. W., Dorin, F., Vargas, V., \& Khan, J. A. M. (2019). Technical efficiency of public district hospitals in Bangladesh: A data envelopment analysis. Cost Effectiveness and Resource Allocation, 17(1), 15-24. https://doi. org/10.1186/s12962-019-0183-6

Akkan, C., Karadayi, M. A., Ekinci, Y., Ülengin, F., Uray, N., \& Karaosmanoğlu, E. (2019). Efficiency analysis of emergency departments in metropolitan areas. SocioEconomic Planning Sciences, 69. https://doi. org/10.1016/j.seps.2019.01.001

Al-Shammari, M. (1999). A multicriteria data envelopment analysis model for measuring the productive efficiency of hospitals. International Journal of Operations and Production Management, 19(9), 879-891. https://doi.org/10.1108/01443579910280205

Anand, S., Ammar, W., Evans, T., Hasegawa, T., Kissimova-Skarbek, K., Langer, A., Lucas, A. O., Makubalo, L., Marandi, A., Meyer, G., Podger, A., Smith, P., \& Wibulpolprasert, S. (2003).
Report of the Scientific Peer Review Group on Health Systems Performance Assessment. In C. J. L. Murray, D. B. Evans (Eds.), Health Systems Performance Assessment: Debates, Methods and Empiricism. Geneve: World Health Organization.

Arocena, P., \& García-Prado, A. (2007). Accounting for quality in the measurement of hospital performance: Evidence from Costa Rica. Health Economics, 167(7), 667-685. https://doi.org/10.1002/hec.1204

AstraZeneca. (2014). The economic cost of cardiovascular disease from 2014-2020 in six European economies (Research paper prepared for AstraZeneca). London: Centre for Economics and Business Research.

Bartak, M., \& Gavurova, B. (2015). Economics and Social Aspects of Long-Term Care in the Context of the Czech Republic and the Slovak Republic EU Membership. Proceedings of 12th International Scientific Conference: Economic Policy in the European Union Member Countries (pp. 35-44). Opava: Silesian University.

Bhat, V. N. (2005). Institutional arrangements and efficiency of health care delivery systems. European Journal of Health Economics, 6(3), 215-222. https://doi.org/10.1007/s10198-0050294-1

Borisov, D., Cicea, C., \& Turlea, C. (2012). DEA model for assessing efficiency in providing health care and management decisions. Management Research and Practice, 4(1), 5-18.

Charnes, A., Cooper, W. W., \& Rhodes, E. (1978). Measuring the efficiency of decision making units. European Journal of Operational Research, 2(6), 429-444. https://doi. org/10.1016/0377-2217(78)90138-8

De-Pablos-Heredero, C., FernándezRenedo, C., Medina-Merodio, J. A. (2015). Technical efficiency and organ transplant performance: A mixed-method approach. International Journal of Environmental Research and Public Health, 12(5), 4869-4888. https://doi.org/10.3390/ijerph120504869

Drake, L., \& Howcroft, B. (1994). Relative efficiency in the branch network of a UK bank: an empirical study. OMEGA, 22(1), 83-90. https://doi.org/10.1016/0305-0483(94)90009-4

Economou, C., \& Giorno, C. (2009). Improving the performance of the public health care system in Greece (Economics Department Working Paper No. 722). Paris: OECD Publishing. https://doi.org/10.1787/221250170007 
Ersoy, K., Kavuncubasi, S., Ozcan, Y. A., \& Harris, J. M. (1997). Technical efficiencies of Turkish hospitals: DEA approach. Journal of Medical Systems, 21(2), 67-74. https://doi. org/10.1023/A:1022801222540

European Heart Network. (2017). European Cardiovascular Disease Statistics 2017 edition. Brussels: European Heart Network.

EUROSTAT Health Data. (2015). Health care resources, Eurostat Health Statistics (database).

Ezzati, M., Lopez, A. D., Rodgers, A., Vander Hoorn, S., \& Murray, C. J. L. (2002). Selected major risk factors and global and regional burden of disease. The Lancet, 360(9343), 1347-1360. https://doi.org/10.1016/ S0140-6736(02)11403-6

Gavurova, B., \& Soltes, M. (2016). System of Day Surgery in Slovakia: Analysis of Pediatric Day Surgery Discrepancies in the Regions and their Importance in Strategy of its Development. E\&M Economics and Management, 19(1), 74-92. https://doi.org/10.15240/tul/001/2016$1-006$

Gok, M. S., \& Sezen, B. (2013). Analyzing the ambiguous relationship between efficiency, quality and patient satisfaction in healthcare services: The case of public hospitals in Turkey. Health Policy, 111(3), 290-300. https://doi. org/10.1016/j.healthpol.2013.05.010

Greene, W. (2004). Distinguishing between heterogeneity and inefficiency: Stochastic frontier analysis of the world health organization's panel data on national health care systems. Health Economics, 13(10), 959980. https://doi.org/10.1002/hec.938

Hadad, S., Hadad, Y., \& Simon-Tuval, T. (2013). Determinants of healthcare system's efficiency in OECD countries. European Journal of Health Economics, 14(2), 253-265. https://doi.org/10.1007/s10198-011-0366-3

Hernandez de Cos, P., \& Moral-Benito, E. (2014). Determinants of health-system efficiency: Evidence from OECD countries. International Journal of Health Care Finance and Economics, 14(1), 69-93. https://doi. org/10.1007/s10754-013-9140-7

Hofmarcher, M., \& Smith, P. (Eds.). (2013). The Health Data Navigator. Your toolkit for comparative performance analysis (EuroREACH product). Vienna: European Centre for Social Welfare Policy and Reserarch.

Hollingsworth, B. (2008). The measurement of efficiency and productivity of health care delivery. Health Economics, 17(10), 1107-1128. https://doi.org/10.1002/hec.1391

Ikegami, N., Hirdes, J. P., \& Carpenter, I. (2002). Measuring the quality of long-term care in institutional and community setting. In P. Smith (Ed.), Measuring up: Improving health system performance in OECD Countries. Paris: OECD Publishing.

Institute of Medicine. (2006). Improving the quality of health care for mental and substance use conditions. Washington, DC: The National Academies Press.

Jacobs, R. (2001). Alternative Methods to Examine Hospital Efficiency: Data Envelopment Analysis and Stochastic Frontier Analysis. Health Care Management Science, 4(2), 103115. https://doi.org/10.1023/A:1011453526849

Kocisova, K., Hass-Symotiuk, M., \& Kludacz-Alessandri, M. (2018). Use of the DEA method to verify the performance model for hospitals. E\&M Economics and Management, 21(4), 125-140. https://doi.org/10.15240/ tul/001/2018-4-009

Pai, D. R., Hosseini, H., \& Brown, R. S. (2019). Does efficiency and quality of care affect hospital closures? Health Systems, 8(1), 17-30. https://doi.org/10.1080/20476965.2017. 1405874

Mitropoulos, P. (2019). Production and quality performance of healthcare services in EU countries during the economic crisis. Operational Research, 1-17. https://doi. org/10.1007/s12351-019-00483-3

Mohan, R., \& Mirmirani, S. (2007). An assessment of OECD health care system using panel data analysis. Southwest Business and Economics Journal, 16, 21-35.

Moran, V., \& Jacobs, R. (2013). An international comparison of efficiency of inpatient mental health care systems. Health Policy, 112(1-2), 88-99. https://doi. org/10.1016/j.healthpol.2013.06.011

Nayar, P., \& Ozcan, Y. A. (2008). Data envelopment analysis comparison of hospital efficiency and quality. Journal of Medical Systems, 32(3), 193-199. https://doi. org/10.1007/s10916-007-9122-8

Özcan, Y. (2008). Health care benchmarking and performance evaluation: an assessment using data envelopment analysis. International Series in Operations Research and Management Science, 120. Basel: Springer Nature.

Ozgen, H., \& Ozcan, Y. A. (2002). A national study of efficiency for dialysis centers: an 
examination of market competition and facility characteristics for production of multiple dialysis outputs. Health Services Research, 37(3), 711732. https://doi.org/10.1111/1475-6773.00045

Reinhardt, U. E., Hussey, P. S., \& Anderson, G. F. (2002). Cross-national comparisons of health systems using OECD data. Health Affairs, 21(3), 169-181. https://doi.org/10.1377/ hlthaff.21.3.169

Retzlaff-Roberts, D., Chang, C. F., \& Rubin, R. M. (2004). Technical efficiency in the use of health care resources: a comparison of OECD countries. Health Policy, 69(1), 55-72. https://doi.org/10.1016/j.healthpol.2003.12.002

Richardson, J., Wildman, J., \& Robertson, I. K. (2003). A critique of the World Health Organisation's evaluation of health system performance. Health Economics, 12(5), 355-366. https://doi.org/10.1002/hec.761

Schwellnus, C. (2009). Achieving higher performance: enhancing spending efficiency in health and education in Mexico (Economics Department Working Papers No. 732). Paris: OECD Publishing.

Sezen, B., \& Gok, M. S. (2016). Analyzing the Efficiencies of Hospitals: an Application of Data Envelopment Analysis. Journal of Global Strategic Management, 2(5), 137-137. https://doi.org/10.20460/jgsm.2011515804

Sharkey, P., Dehaemer, M., \& Horn, S. (1993). Assessing the severity of patient's illness to better manage health care resources. Interfaces, 23(4), 12-20.

Simar, L., \& Wilson, P. W. (2007). Estimation and inference in two-stage, semi-parametric models of production processes. Journal of Econometrics, 136(1), 31-64. https://doi. org/10.1016/j.jeconom.2005.07.009

Soltes, M., \& Gavurova, B. (2014). Identification of the Functionality Level of Day Surgery in Slovakia. Ekonomický časopis, 62(10), 1031-1051. https://doi.org/10.15240/ tul/001/2016-1-006

Spinks, J., \& Hollingsworth, B. (2009). Cross-country comparisons of technical efficiency of health production: a demonstration of pitfalls. Applied Economics, 41(4), 417-427. https://doi.org/10.1080/00036840701604354

Stancheva, N., \& Angelova, V. (2004). Measuring the efficiency of university libraries using data envelopment analysis. Inforum, 32(1990), 136-146.

Starfield, B. (1973). Health services research: a working model. The New England Journal of Medicine, 289(2), 132-136. https://doi.org/10.1056/NEJM197307192890305

Stefko, R., Gavurova, B., \& Korony, S. (2016). Efficiency Measurement in Healthcare Work Management Using Malmquist Indices. Polish Journal of Management Studies, 13(1), 168-180. https://doi.org/10.17512/ pjms.2016.13.1.16

Szabo, S., Mihalčová, B., Gallo, P., \& Ivaničková, M. (2018). Evaluating efficiency in specialized hospital facilities - developing the model by way of the discriminant analysis. E\&M Economics and Management, 21(3), 88-106. https://doi.org/10.15240/tul/001/2018-3-006

Varabyova, Y., \& Schreyögg, J. (2013). International comparisons of the technical efficiency of the hospital sector: Panel data analysis of OECD countries using parametric and non-parametric approaches. Health Policy, 112(1-2), 70-79. https://doi.org/10.1016/j. healthpol.2013.03.003

Wang, R., \& Yu, M. (2006). Evaluating the efficiency of hospital's departments using DEA. In Proceedings of IEEE international conference on service operations and logistics, and informatics (pp. 1167-1170). Soli.

Williams, A. (2003). Science or marketing at WHO? A commentary on 'World Health 2000'. Health Economics, 10(2), 93-100. https://doi. org/10.1002/hec.594

Yawe, B. L., \& Kavuma, S. N. (2008). Technical efficiency in the presence of desirable and undesirable outputs: A case study of selected district referral hospitals in Uganda. Health Policy and Development, 6(1), 37-53. 